\title{
RAPID THERMAL PROCESSING OF IMPLANTED GaN UP TO $1500{ }^{\circ} \mathrm{C}$
}

\author{
X. A. Cao,* S. J. Pearton,* R. K. Singh,* C. R. Abernathy,* J. Han,** R. J. Shul,** D. J. \\ Rieger,** J. C. Zolper, $* * *$ R. G. Wilson, $* * * *$ M. Fu, ${ }^{* * * * *}$ J. A. Sekhar, $* * * * *$ H. J. Guo \\ $* * * * * *$ and S. J. Pennycook****** \\ *Department of Materials Science and Engineering, University of Florida, Gainesville, FL \\ 32611, USA \\ **Sandia National Laboratories, Albuquerque, NM 87185, USA \\ ***Office of Naval Research, Arlington, VA 22217, USA \\ ****Consultant, Stevenson Ranch, CA 91381, USA \\ *****Micropyretics Heaters International, Inc. Cincinnati, OH 45215, USA \\ *******ak Ridge National Laboratory, Solid State Division, Oak Ridge, TN 37831,USA
}

\section{Cite this article as: MRS Internat J. Nitride Semicond. Res. 4S1, G6.33(1999)}

\begin{abstract}
$\mathrm{GaN}$ implanted with donor(Si, $\mathrm{S}, \mathrm{Se}, \mathrm{Te})$ or acceptor $(\mathrm{Be}, \mathrm{Mg}, \mathrm{C})$ species was annealed at 900-1500 ${ }^{\circ} \mathrm{C}$ using AlN encapsulation. No redistribution was measured by SIMS for any of the dopants and effective diffusion coefficients are $\leq 2 \times 10^{-13} \mathrm{~cm}^{2} \cdot \mathrm{s}^{-1}$ at $1400{ }^{\circ} \mathrm{C}$, except Be, which displays damage-enhanced diffusion at $900{ }^{\circ} \mathrm{C}$ and is immobile once the point defect concentration is removed. Activation efficiency of $\sim 90 \%$ is obtained for Si at $1400{ }^{\circ} \mathrm{C}$. TEM of the implanted material shows a strong reduction in lattice disorder at $1400-1500{ }^{\circ} \mathrm{C}$ compared to previous results at $1100{ }^{\circ} \mathrm{C}$. There is minimal interaction of the sputtered AlN with GaN under our conditions, and it is readily removed selectively with $\mathrm{KOH}$.
\end{abstract}

\section{INTRODUCTION}

The study of implanted species in $\mathrm{GaN}$ to this point has focused on activation of $\mathrm{Si}^{+}$or $\mathrm{O}^{+}$for n-type doping, $\mathrm{Mg}^{+}$or $\mathrm{Ca}^{+}$for p-type doping, or use of $\mathrm{He}^{+}, \mathrm{N}^{+}$or $\mathrm{H}^{+}$for isolation[1-15]. For practical applications, the focus has been on the use of implantation for improving ohmic contact resistance on heterostructure field-effect transistors[16], and to producing p-n junctions for fabrication of junction field-effect transistors[12] and for light-emitting diodes[4]. At high implant doses $\left(\geq 5 \times 10^{14} \mathrm{~cm}^{-2}\right)$ it is clear that conventional rapid thermal annealing (RTA) at $1100-1200{ }^{\circ} \mathrm{C}$ can activate the dopants but not remove the ion-induced structural damage $[14,15]$. At higher annealing temperatures $\left(\geq 1400{ }^{\circ} \mathrm{C}\right)$ it is difficult to provide a sufficiently high $\mathrm{N}_{2}$ pressure to prevent dissociation of the GaN surface. Three different approaches have been reported - the first is use of an $\mathrm{NH}_{3}$ ambient in a metal organic chemical vapor deposition (MOCVD) reactor[17], the second is use of a high $\mathrm{N}_{2}$ overpressure (15 kbar) in a GaN bulk crystal growth apparatus[14], and the third is use of an AlN encapsulant to prevent nitrogen loss from the GaN[18]. The third approach is clearly the most convenient.

The amount of residual lattice damage in the implanted GaN after annealing is a function of ion dose - for the relatively high doses needed for source/drain doping, it has been shown previously that annealing temperatures of $\geq 1400{ }^{\circ} \mathrm{C}$ are desirable. We have found that $\mathrm{Si}$, the most common n-type dopant, shows no detectable redistribution at $1400{ }^{\circ} \mathrm{C}$, and that annealing 
at this temperature produces activation percentages of $\geq 90 \%[19,20]$. Annealing at $1500{ }^{\circ} \mathrm{C}$ led to a reduction in both sheet electron concentration and electron mobility, which is consistent with self-compensation through site-switching of the Si. There is no available information on the other donor species, or on the possible acceptor dopants, in terms of their redistribution during ultra-high temperature annealing. In this paper we report on a Secondary Ion Mass Spectrometry (SIMS) study of GaN implanted with the group VI donors, S, Se and Te, and the acceptor species $\mathrm{Mg}, \mathrm{Be}$ and $\mathrm{C}$. Only $\mathrm{Be}$ is found to show redistribution during annealing, emphasizing the extremely good high temperature stability of dopants in GaN. We have also examined the activation kinetics of some of the implanted species.

\section{EXPERIMENTAL}

Layers of $\mathrm{GaN} 2-3 \mu \mathrm{m}$ thick were grown at $\sim 1040{ }^{\circ} \mathrm{C}$ on c-plane $\mathrm{Al}_{2} \mathrm{O}_{3}$ by atmospheric pressure Metal Organic Chemical Vapor Deposition(MOCVD), using triethylgallium and ammonia. From x-ray diffraction and photoluminescence measurements we know this material is typical of the current state-of-the-art heteroepitaxial GaN.

The samples were implanted at $25^{\circ} \mathrm{C}$ with $150 \mathrm{keV}{ }^{24} \mathrm{Mg}^{+}, 80 \mathrm{keV}{ }^{9} \mathrm{Be}^{+}, 80 \mathrm{keV}{ }^{12} \mathrm{C}^{+}, 200$ $\mathrm{keV}{ }^{32} \mathrm{~S}^{+}, 300 \mathrm{keV}{ }^{80} \mathrm{Se}^{+}$, or $600 \mathrm{keV}{ }^{128} \mathrm{Te}^{+}$ions, at doses of $3-5 \times 10^{14} \mathrm{~cm}^{-2}$. This puts the projected range, $R_{p}$, of the implanted species at least $1500 \AA$ into the $\mathrm{GaN}$ in all cases, avoiding effects due to near-surface point defect injection. The samples were capped with $\sim 1000 \AA$ of reactively sputtered $\mathrm{AlN}$, and annealed at temperatures of $900-1450{ }^{\circ} \mathrm{C}$ under a $\mathrm{N}_{2}$ ambient in the Zapper $^{\mathrm{TM}}$ furnace described previously[14]. The dwell time at the peak temperature was $\sim 10$ secs. After annealing, the AlN was selectively etched in aqueous $\mathrm{KOH}$ at $80^{\circ} \mathrm{C}[15]$. The atomic distributions before and after annealing were measured by SIMS, and the data quantified using the as-implanted sample as a standard. The electrical properties were examined by Hall measurement, and the data was recorded at $25{ }^{\circ} \mathrm{C}$ in all cases.

\section{RESULTS AND DISCUSSION}

\section{(a) Residual Damage}

Figure 1 shows a plan view TEM and selected area electron diffraction pattern from a Siimplanted sample $\left(150 \mathrm{keV}, 5 \times 10^{15} \mathrm{~cm}^{-2}\right)$ after annealing at $1100{ }^{\circ} \mathrm{C}$ for 10 secs. This is a high dose implant of the type used for making $\mathrm{n}^{+}$ohmic contact regions, and represents a worst-case scenario in terms of damage removal. The sample is still single-crystal as determined by the diffraction pattern, but contains a high density of extended defects $\left(\sim 10^{10} \mathrm{~cm}^{-2}\right)$. This is consistent with past reports of high backscattering yields in implanted GaN annealed at these conditions[14,15]. We ascribe these defects to the formation of dislocation loops in the incompletely repaired lattice.

By sharp contrast, annealing at $1400{ }^{\circ} \mathrm{C}$ for 10 secs brings a substantial reduction in the implant-induced defects, as shown in Figure 2. The sample is again single-crystal, but the only contrast in the TEM plan view is due to the lower density $\left(\sim 10^{9} \mathrm{~cm}^{-2}\right)$ of threading dislocations arising from lattice-mismatch in the heteroepitaxy. This appears to correlate well with the fact that the highest electron mobility and carrier density in these samples was observed for $1400{ }^{\circ} \mathrm{C}$ annealing. Clearly the ultra-high temperature annealing is required to completely remove lattice damage in $\mathrm{GaN}$ implanted with high doses. However it may not be needed in lower dose material $\left(\leq 5 \times 10^{13} \mathrm{~cm}^{-2}\right)$ where the amount of damage created is correspondingly less. 

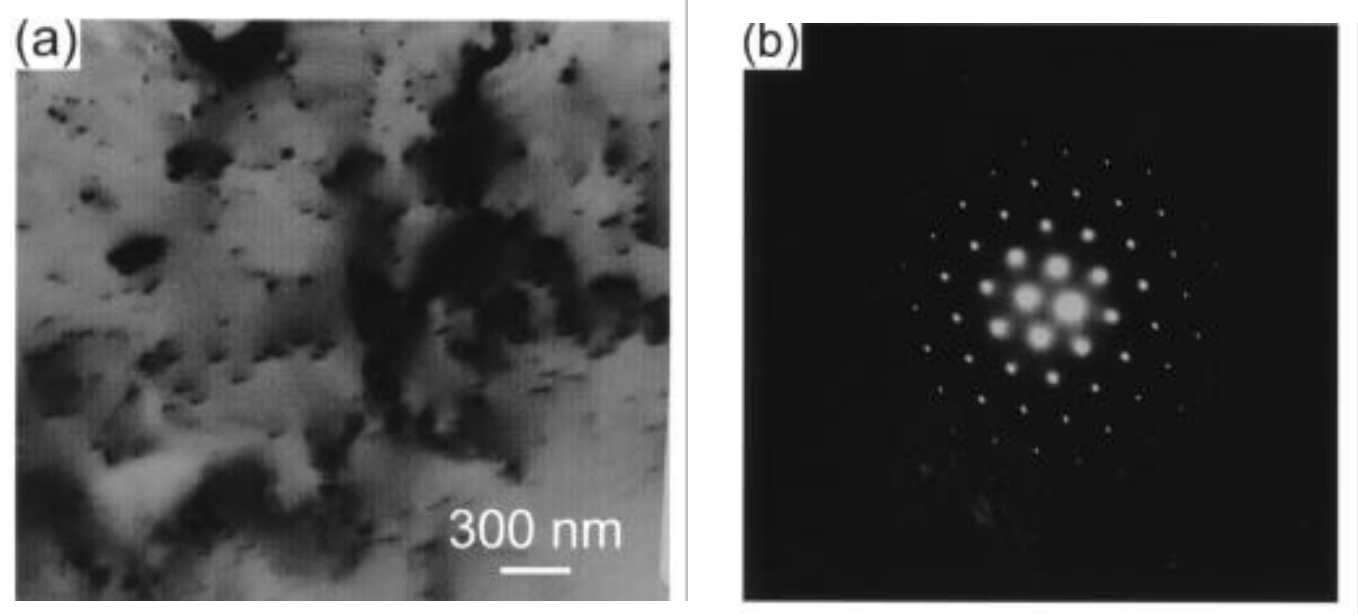

Fig. 1. (a) TEM plan view and (b) selected area diffraction pattern from $\mathrm{Si}^{+}$implanted $\mathrm{GaN}\left(5 \times 10^{15} \mathrm{~cm}^{-2}, 150 \mathrm{keV}\right)$ after $1100^{\circ} \mathrm{C}, 10 \mathrm{sec}$ annealing.
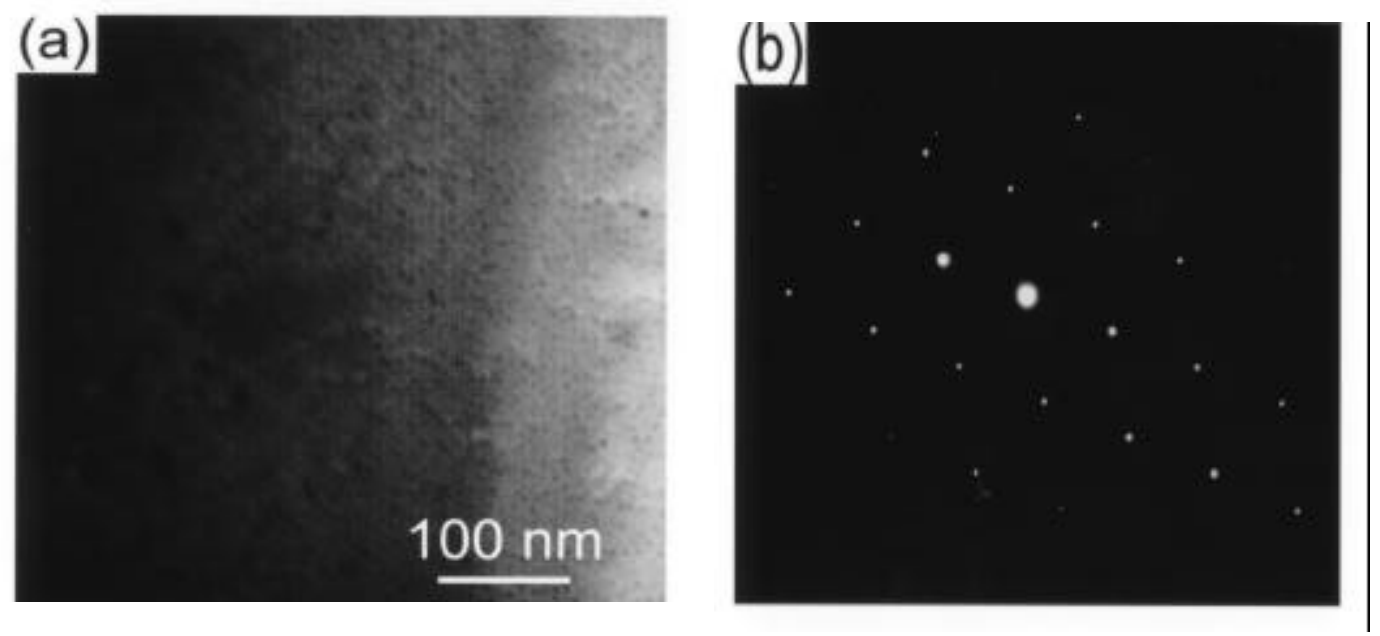

Fig. 2. (a) TEM plan view and (b) selected area diffraction pattern from $\mathrm{Si}^{+}$implanted $\mathrm{GaN}\left(5 \times 10^{15} \mathrm{~cm}^{-2}, 150 \mathrm{keV}\right)$ after $1400{ }^{\circ} \mathrm{C}, 10 \mathrm{sec}$ annealing.

\section{(b) Dopant Activation}

\section{(i) Donors}

Figure 3(top) shows an Arrhenius plot of $\mathrm{S}^{+}$activation in GaN. The sheet carrier concentration measured at $25{ }^{\circ} \mathrm{C}$ shows an activation energy of $3.16 \mathrm{eV}$ for the annealing temperature range between $1000-1200{ }^{\circ} \mathrm{C}$ and basically saturates thereafter. The maximum sheet electron density, $\sim 7 \times 10^{13} \mathrm{~cm}^{-2}$, corresponds to a peak volume density of $\sim 5 \times 10^{18} \mathrm{~cm}^{-3}$. This is well below that achieved with $\mathrm{Si}^{+}$implantation and annealing $\left(>10^{20} \mathrm{~cm}^{-3}\right)[17,20]$. In the latter case the carrier density showed an activation energy of $5.2 \mathrm{eV}$. The physical origin of this activation energy contains several components - basically it is the energy required to move an implanted ion onto a substitutional lattice site and for it to show electrical activity. This latter 
requirement means that compensating defects must also be annealed out. Even though implanted $\mathrm{Si}^{+}$at the same dose showed evidence of site-switching and self-compensation, it still produces a higher peak doping level than the non-amphoteric donor $S$, which is only slightly heavier $\left({ }^{32} \mathrm{~S}\right.$ vs. ${ }^{28} \mathrm{Si}$ ). From temperature-dependant Hall measurements, we find a $\mathrm{S}^{+}$donor ionization level of $48 \pm 10 \mathrm{meV}$, so that the donors are fully ionized at room temperature.

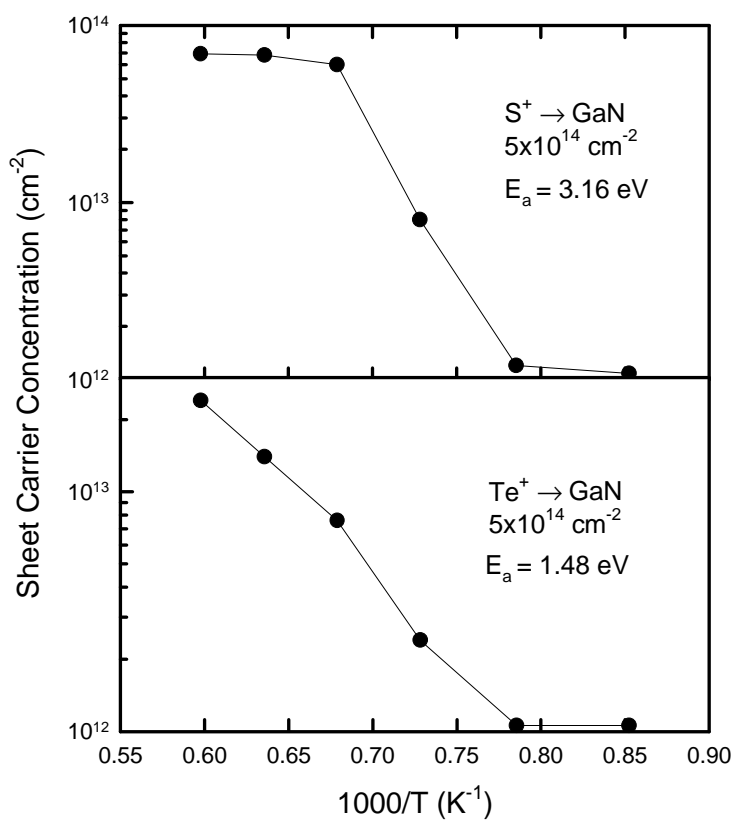

Fig. 3. Arrhenius plot of sheet electron density in $\mathrm{S}^{+}$(top) or $\mathrm{Te}^{+}$(bottom) implanted $\mathrm{GaN}$ versus annealing temperature.

Similar data is shown in Figure 3(bottom) for $\mathrm{Te}^{+}$implantation. The activation starts around the same temperature as for $\mathrm{S}$, but much lower sheet electron densities are obtained, the activation energy is significantly lower $(1.5 \mathrm{eV})$ and the carrier concentration does not saturate, even at $1400{ }^{\circ} \mathrm{C}$. It is likely that because of the much greater atomic weight of ${ }^{128} \mathrm{Te}$, even higher annealing temperatures would be required to remove all its associated lattice damage, and that the activation characteristics are still being dominated by this defect removal process. Residual lattice damage from the implantation is electrically active in all III-V semiconductors, producing either high resistance behaviors(GaAs) or residual n-type conductivity(InP, GaN). The only data available on group VI doping in epitaxial material is from Se-doped MOCVD material, where maximum electron concentrations of $2 \times 10^{18}-6 \times 10^{19} \mathrm{~cm}^{-3}$ were achieved[21,22]. These are also below the values reported for Si-doping, and suggests the group VI donors do not have any advantage over Si for creation of n-type layers in GaN. From limited temperature-dependent Hall data, we estimate the Te ionization level to be $50 \pm 20 \mathrm{meV}$.

No redistribution of any of the donor species was observed during annealing up to $1500{ }^{\circ} \mathrm{C}$, suggesting the diffusion coefficient is $\leq 2 \times 10^{-13} \mathrm{~cm}^{2} \cdot \mathrm{s}^{-1}$ for $\mathrm{S}, \mathrm{Se}$, Te and Si at this temperature.

\section{(ii) Acceptors}

The effects of post-implant annealing temperature on the sheet carrier concentrations in $\mathrm{Mg}^{+}$ and $\mathrm{C}^{+}$implanted $\mathrm{GaN}$ are shown in Figure 4. There are two important features of the data: first, 
we did not achieve p-type conductivity with carbon, and second only $\sim 1 \%$ of the $\mathrm{Mg}$ produces a hole at $25{ }^{\circ} \mathrm{C}$. Carbon has been predicted previously to have a strong self-compensation effect[23], and it has been found to produce p-type conductivity only in metal organic molecular beam epitaxy where its incorporation on a N-site is favorable[24]. Based on an ionization level of $\sim 170 \mathrm{meV}$, the hole density in $\mathrm{Mg}$-doped $\mathrm{GaN}$ would be calculated to be $\sim 10 \%$ of the $\mathrm{Mg}$ acceptor concentration when measured at $25^{\circ} \mathrm{C}$. In our case we see an order of magnitude less holes than predicted. This should be related to the existing n-type carrier background in the material and perhaps to residual lattice damage which is also n-type in GaN, At the highest annealing temperature $\left(1400{ }^{\circ} \mathrm{C}\right)$, the hole density falls, which could be due to $\mathrm{Mg}$ coming out of the solution or to the creation of further compensating defects in the GaN.

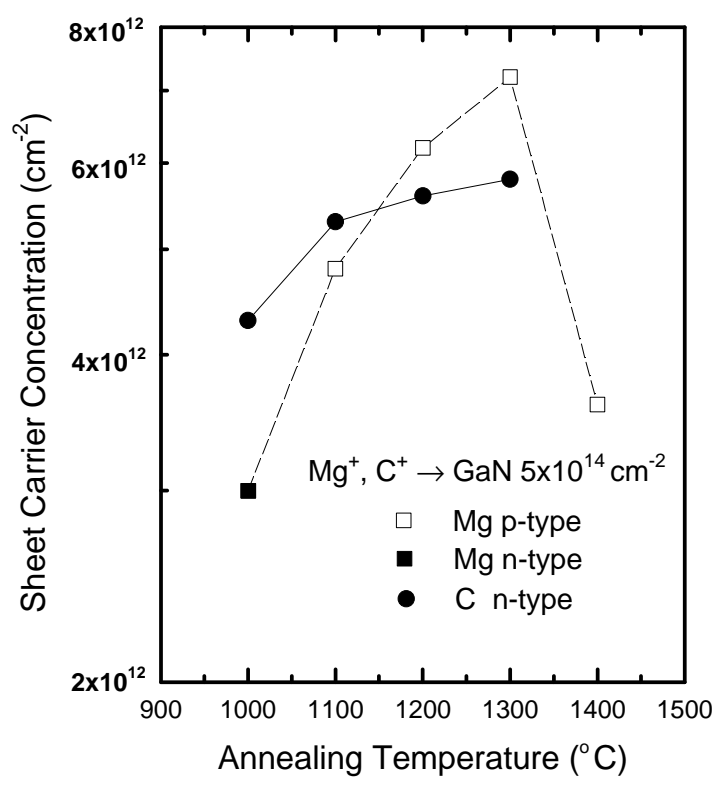

Fig. 4. Sheet carrier densities in $\mathrm{Mg}^{+}$or $\mathrm{C}^{+}$implanted $\mathrm{GaN}$ as a function of annealing temperature.

We did not observe any redistribution of either $\mathrm{Mg}$ or $\mathrm{C}$ for annealing up to $1450{ }^{\circ} \mathrm{C}$, indicating a diffusivity of $\leq 2 \times 10^{-13} \mathrm{~cm}^{2} \cdot \mathrm{s}^{-1}$ at this temperature. In the particular case of implanted $\mathrm{Be}$, there was an initial broadening of the profile at $900{ }^{\circ} \mathrm{C}$, corresponding to an effective diffusivity of $\sim 5 \times 10^{-13} \mathrm{~cm}^{2} \cdot \mathrm{sec}^{-1}$ at this temperature. However there was no subsequent redistribution at temperatures up to $1200{ }^{\circ} \mathrm{C}$. Implanted Be shows several types of anomalous diffusion in GaAs, including up-hill diffusion and movement in the tail of the profile, in addition to normal concentration-dependent diffusion, which also result from the non-equilibrium concentrations of point defects created by the nuclear stopping process of the implanted ions. It appears that in $\mathrm{GaN}$, the interstitial Be undergoes a type of transient-enhanced diffusion until these excess point defects are removed by annealing, at which stage the Be is basically immobile.

\section{SUMMARY AND CONCLUSIONS}


Common acceptor and donor species have been implanted into $\mathrm{GaN}$ at room temperature, and subsequently annealed up to $1500{ }^{\circ} \mathrm{C}$. With the exception of $\mathrm{Be}$, which shows an apparent damage-assisted redistribution at $900{ }^{\circ} \mathrm{C}$, none of the species show detectable motion under these conditions. This is promising for the fabrication of $\mathrm{GaN}$-based power devices, which require creation of doped well or source/drain regions by implantation. The low diffusivities of implanted dopants in $\mathrm{GaN}$ means that junction placement should be quite precise and there will be less problems with lateral diffusion of the source/drain regions towards the gate. Finally, the results show the effectiveness of the AIN cap in protecting the GaN surface from dissociation, since if any of the surface was degraded during annealing, the implant profiles would no longer overlap.

\section{ACKNOWLEDGEMENTS}

The work of UF is partially supported by a DARPA/EPRI grant MDA 972-98-1-0006 (D. Radack/J. Melcher) and by an NSF grant DMR 9732865 (L. Hess). Sandia is a multiprogram laboratory operated by Sandia Corporation, a Lockheed-Martin company, for the US Department of Energy under contract No. DEAC04-94 AL 85000. The work of R. G. Wilson is partially supported by an ARO grant.

\section{REFERENCES}

1. J. C. Zolper, J. Cryst. Growth 178175 (1997).

2. J. C. Zolper, in GaN and Related Materials, Vol. 2 of Optoelectronic Properties of Semiconductors and Superlattices. (Gordon and Breach, NY 1997).

3. R. G. Wilson, Proc. Electrochem. Soc. Vol. 95-21 152 (1995).

4. H. P. Maruska, M. Lioubtchenko, T. G. Tetreault, M. Osinski, S. J. Pearton, M. Schurman, R. Vaudo, S. Sakai, Q. Chen and R. J. Shul, Mat. Res. Soc. Symp. Proc. 483345 (1998).

5. J. C. Zolper, H. H. Tan, J. S. Williams, J. Zou, D. J. H. Cockayne, S. J. Pearton, M. H. Crawford and R. F. Karlicek Jr., Appl. Phys. Lett. 702729 (1997).

6. S. C. Binari, H. B. Dietrich, G. Kelner, L. B. Rowland, K. Doverspike and D. K. Wickenden, J. Appl. Phys. 783008 (1995).

7. C. Liu, B. Mensching, M. Zeitler, K. Volz, and B. Rauschenbach, Phys. Rev. B 572530 (1998).

8. C. Ronning, N. Dalmer, M. Deicher, M. Restle, M. D. Bremser, R. F. Davis and H. Hofsass, Mat. Res. Soc. Symp. Proc. Vol. 468407 (1997).

9. H. Kobayashi, W. M. Gibson, Appl. Phys. Lett. 731406 (1998).

10. T. Suski, J. Jun, M. Leszczynski, H. Teisseyre, I. Grzegory, S. Porowski, J. M. Baranowski, A. Rockett, S. Strite, A. Stanert, A. Turos, H. H. Tan, J. S. Williams and C. Jagadish, Mat. Res. Soc. Symp. Proc. Vol. 482703 (1998).

11. S. J. Pearton, C. R. Abernathy, C. B. Vartuli, J. C. Zolper, C. Yuan and R. A. Stall, Appl. Phys. Lett. 682273 (1996).

12. J. C. Zolper, R. J. Shul, A. G. Baca, R. G. Wilson, S. J. Pearton and R. A. Stall, Appl. Phys. Lett. 682273 (1996).

13. J. C. Zolper, R. G. Wilson, S. J. Pearton and R. A. Stall, Appl. Phys. Lett. 681945 (1996).

14. J. C. Zolper, J. Han, S. B. Van Deusen, R. M. Biefeld, M. H. Crawford, J. Han, T. Suski, J. M. Baranowski and S. J. Pearton, Mat. Res. Soc. Symp. Proc. 482609 (1998).

15. H. H. Tan, J. S. Williams, J. Zou, D. J. H. Cockayne, S. J. Pearton and R. A. Stall, Appl. Phys. Lett. 692364 (1996). 
16. J. Burm, K. Chu, W. A. Davis, W. J. Schaff, L. F. Eastman and T. J. Eustis, Appl. Phys. Lett. 70464 (1997).

17. J. C. Zolper, J. Han, R. M. Biefeld, S. B. Van Deusen, W. R. Wampler, D. J. Reiger, S. J. Pearton, J. S. Williams, H. H. Tan and R. Stall, J. Electron. Mater. 27179 (1998).

18. J. C. Zolper, D. J. Reiger, A. G. Baca, S. J. Pearton, J. W. Lee and R. A. Stall, Appl. Phys. Lett. 69538 (1996).

19. M. Fu, V. Sarvepalli, R. K. Singh, C. R. Abernathy, X. A. Cao, S. J. Pearton and J. A. Sekhar, Mat. Res. Soc. Symp. Proc. 483345 (1998).

20. X. A. Cao, C. R. Abernathy, R. K. Singh, S. J. Pearton, M. Fu, V. Sarvepalli, J. A. Sekhar, J. C. Zolper, D. J. Rieger, J. Han, T. J. Drummond, R. J. Shul and R. G. Wilson, Appl. Phys. Lett. 73229 (1998).

21. M. S. Feng, J. D. Guo and G. C. Chi, Proc. Electrochem Soc. Vol. 95-21 43 (1995).

22. C. C. Yi and B. W. Wessels, Appl. Phys. Lett. 693026 (1996).

23. P. Bogulawski, E. L. Briggs and J. Bernholc, Phys. Rev. B 5117255 (1995).

24. C. R. Abernathy, J. D. MacKenzie, S. J. Pearton and W. S. Hobson, Appl. Phys. Lett. 66 1969 (1995). 